\title{
Elevated glycosylated hemoglobin levels and their interactive effects on hypertension risk in nondiabetic Chinese population: a cross-sectional survey
}

\author{
Jian Song ${ }^{1}$, Nana Wei ${ }^{2}$, Yingying Zhao ${ }^{3}$, Yuhong Jiang ${ }^{1}$, Xuesen $\mathrm{Wu}^{1}$ and Huaiquan Gao ${ }^{1 *}$ (D)
}

\begin{abstract}
Background: Abnormal glucose metabolism has been suggested to be involved in the development of hypertension. This study investigated the effect of the association and potential interaction of glycosylated hemoglobin (HbA1c) and other factors on the risk of hypertension among Chinese nondiabetic adults.

Methods: As a cross-sectional survey, the current work deployed a questionnaire survey, anthropometric tests, and biochemical measures for each of the eligible participants. The HbA1c levels were quantified and grouped by quartiles. Correlations between $\mathrm{HbAlc}$ and hypertension, isolated systolic hypertension (ISH), and isolated diastolic hypertension (IDH) risk were investigated by logistic analyses. For evaluating the interactive effects, the parameters of relative excess risk due to interaction (RERI), attributable proportion due to interaction (AP), and synergy index (SI) were calculated, respectively.
\end{abstract}

Results: In the current study, 1462 nondiabetic subjects were enrolled. In total, the prevalence rates of hypertension, ISH and IDH were 22.4, 9.6 and 4.5\%, respectively. When HbA1c levels were grouped by quartile, it was revealed that the prevalence rates of hypertension and ISH were substantially elevated across groups ( $P_{\text {for trend }}<0.001$ ). In the multivariable logistic regression analyses, in comparison with the first quartile of $\mathrm{HbA} 1 \mathrm{c}$, the normalized $\mathrm{OR}$ for hypertension risk was 1.90 ( $95 \%$ Cl: 1.28-2.80) for the highest quartile. Also, the risk of ISH was significantly increased with $\mathrm{HbA} 1 \mathrm{c}$ level in the highest quartile relative to in the bottom quartile (OR: 2.23,95\% Cl:1.47-3.71). However, no significant relationship between the HbA1c level and IDH risk was observed (OR: 1.78, 95\% Cl: 0.82-3.84). Eventually, it was demonstrated from the interactive effect analysis that HbA1c significantly interacted with abdominal obesity (RERl: 1.48, 95\% Cl: 0.38-2.58; AP: 0.37, 95\% Cl: 0.14-0.60 and SI: 1.96, 95\% Cl: 1.06-3.62) and family history of hypertension (AP: $0.37,95 \% \mathrm{Cl}: 0.05-0.70)$ in influencing the risk of hypertension in nondiabetic participants.

Conclusion: Higher HbA1c levels significantly enhanced the risk of hypertension and ISH, but not IDH among Chinese nondiabetic adults. Moreover, the risk of hypertension was also aggravated by the upregulated HbA1c in a synergistic manner alongside abdominal obesity and family history of hypertension.

Keywords: Hypertension, HbA1c, Obesity, Interaction

\footnotetext{
* Correspondence: ghabbmc@sina.com

${ }^{1}$ School of public health, Bengbu medical college, Bengbu 233000, Anhui Province, China

Full list of author information is available at the end of the article
}

C C The Author(s). 2020 Open Access This article is licensed under a Creative Commons Attribution 4.0 International License, which permits use, sharing, adaptation, distribution and reproduction in any medium or format, as long as you give appropriate credit to the original author(s) and the source, provide a link to the Creative Commons licence, and indicate if changes were made. The images or other third party material in this article are included in the article's Creative Commons licence, unless indicated otherwise in a credit line to the material. If material is not included in the article's Creative Commons licence and your intended use is not permitted by statutory regulation or exceeds the permitted use, you will need to obtain permission directly from the copyright holder. To view a copy of this licence, visit http://creativecommons.org/licenses/by/4.0/ The Creative Commons Public Domain Dedication waiver (http://creativecommons.org/publicdomain/zero/1.0/) applies to the data made available in this article, unless otherwise stated in a credit line to the data. 
As one of the most common cardiovascular diseases, hypertension has become a prominent social public health problem globally [1]. A national survey of 451,755 participants from 31 provinces in China estimated that nearly 244.5 million people were suffering from hypertension [2]. What was worse, low rates of awareness, treatment, and control of hypertension were reported $[2,3]$. Additionally, several meta-analyses have proved that hypertension was dramatically associated with the increased risk of a series of diseases such as Parkinson's disease, stroke, and cancer [4-6]. It was believed that $54 \%$ of stroke cases and $47 \%$ of ischemic disease cases were attributable to hypertension worldwide [7]. Consequently, distinctly investigating the risk factors and effective predictors of hypertension are essential for alleviating the public health burden.

Often accompanied by abnormal glucose metabolism, hypertension may be observable in greater than twothirds of patients suffering from type 2 diabetes [8]. It was suggested that the development of hypertension is consistent with hyperglycemia. Insulin resistance (IR), hyperinsulinemia, and the excitatory effects of hyperglycemia itself may be the underlying mechanisms of hypertension [8]. HbA1c, as a stable indicator of longterm glycemia, can precisely reflect the stability of glycemic control within nearly 8-12 weeks and was also correlated with defects of pancreatic $\beta$-cell function, as well as the degree of IR $[9,10]$. Other evidence has increasingly demonstrated that not only patients with a higher risk of developing diabetes but also those with cardiovascular diseases could be identified by HbA1c level $[11,12]$. Research has reported a significant relationship exists between a high-normal HbAlc level and an increased risk of arterial stiffness in individuals without type 2 diabetes [13]. To date, a few studies have analyzed the relationship between $\mathrm{HbA1c}$ and the risk of hypertension, and the conclusions were inconsistent. Additionally, ISH and IDH, as two subtypes of hypertension, were shown to have different pathophysiological mechanisms and distinctive risk factors $[14,15]$. However, the relationship between HbA1c level and different types of hypertension remained unclear. Furthermore, as a multifactorial disease, hypertension was affected by a series of factors related to its occurrence and development. For instance, a remarkable interaction between smoking and overweightness has an impact on hypertension risk [16]. A case-control study in the Chinese population indicated that body mass index (BMI) dramatically interacted with a family history of hypertension to influence the risk of hypertension [17]. Conclusively, we hypothesized that HbA1c may have an effect in combination with other factors on the risk of hypertension.

Using data from the present cross-sectional survey, we aimed at: (1) investigating the association between HbA1c and risk of hypertension, ISH, IDH, respectively.
(2) exploring potentially interactive effects of HbA1c together with other factors on the risk of hypertension.

\section{Methods \\ Subjects}

The participants in this study were recruited from a project labeled as an initiative aimed at "creating a provincial demonstration area of chronic disease management in the community," which was conducted in Longzihu, Bengbu, China in 2015 and mainly designed to identify the epidemiological characteristics of chronic noncommunicable diseases among the local residents. Multistage random sampling was utilized to select qualified subjects. The exclusion criteria included: (1) unable to complete the survey independently, (2) having a previous diagnosis of psychosis; or (3) temporary residents. In this study, for the purpose of analyzing the data of nondiabetics, those patients with diagnosed diabetes, a fasting plasma glucose (FPG) value of $7.0 \mathrm{mmol} / \mathrm{L}$ or higher, or receiving treatment for hyperglycemia were also excluded [18]. Eventually, 1462 nondiabetic subjects were selected. All of the participants were required to complete the whole survey in community clinics and each signed an informed consent form. The study protocol was approved by the ethics committee of Bengbu Medical College.

\section{Data collection}

The data of general characteristics and lifestyle information were gathered by qualified investigators based on a face-to-face questionnaire survey. The established questionnaire included information about birth date, gender, smoking status, marital status ("currently married" or "currently not married"), educational level ("middle school graduate or lower" or "high school graduate or above"), income (" $\leq 2,000$ yuan" or "> 2000 yuan"), selfreported disease history, and family history of hypertension (yes or no). A positive family history of hypertension was defined as at least one parent or sibling with hypertension.

Blood pressure (BP) was measured based on unified standardized measurement methods [19]. Each subject was required to take a rest at least for $10 \mathrm{~min}$ in a quiet room prior to undergoing triple measurements of BP. The average results were calculated and adopted. If the difference was greater than $5 \mathrm{mmHg}$, the subject was required to undergo measurement of the BP again after a rest for at least $10 \mathrm{~min}$. Hypertension was defined as when the systolic BP (SBP) was greater than or equal to $140 \mathrm{mmHg}$ or diastolic BP (DBP) was greater or equal to $90 \mathrm{mmHg}$ or the patient was using hypertension medications [20]. Individuals with an SBP of $140 \mathrm{mmHg}$ or more and DBP of less than $90 \mathrm{mmHg}$ were defined as having ISH, while IDH was defined as when the SBP was less than $140 \mathrm{mmHg}$ and DBP was $90 \mathrm{mmHg}$ or more 
[20]. The height and weight of each participant were measured with light indoor clothing. BMI was calculated as weight $(\mathrm{kg}) /$ height $^{2}\left(\mathrm{~m}^{2}\right)$. Participants with BMI values of $28 \mathrm{~kg} / \mathrm{m}^{2}$ or more were regarded as showing general obesity [21]. For the measurement of waist circumference (WC), subjects were required to maintain a fasting state and an upright position. Abdominal obesity in males and females were defined as a WC of $90 \mathrm{~cm}$ or more or $85 \mathrm{~cm}$ or more, respectively [22]. Venous blood samples were collected in the morning and all the participants were required to complete overnight fasting for more than $8 \mathrm{~h}$. Subsequently, HbA1c, FPG, and triglycerides (TG) were analyzed.

\section{Statistical methods}

Statistical analyses were conducted using the R software. Normally distributed data were described as means \pm standard deviations (SD), which were further compared based on t-test. For non-normally distributed data, they were described as medians $\left(\mathrm{P}_{25}, \mathrm{P}_{75}\right)$ and compared by the Wilcoxon rank-sum test. Additionally, percentages (\%) were applied for the representation of categorical variables, which were subsequently analyzed using the chi-squared test. HbA1c levels could be classified into four quartiles (Q1-Q4). Univariate and multivariate logistic regression models were designed with odds ratios (ORs) and corresponding 95\% confidence intervals (95\% CIs). In order to obtain the best threshold of HbA1c to predict hypertension among nondiabetic subjects, receiver operating characteristic (ROC) curve analysis was adopted. Finally, three indicators reflecting interactive effects, including (1) the relative excess risk due to interaction (RERI), (2) attributable proportion due to interaction (AP), and (3) the synergy index (SI), were calculated. They were defined as follows: RERI $=\mathrm{OR}_{11}-$ $\mathrm{OR}_{10}-\mathrm{OR}_{01}+1, \mathrm{AP}=\mathrm{RERI} / \mathrm{OR}_{11}$, and $\mathrm{SI}=\left(\mathrm{OR}_{11}-1\right) /$ $\left(\mathrm{OR}_{01}-1\right)+\left(\mathrm{OR}_{10}-1\right)[23,24]$. As an example, when we analyzed the interaction between $\mathrm{HbAlc}$ and general obesity, $\mathrm{OR}_{11}$ represented the effect of hypertension on individuals who had a increased level of HbA1c and BMI of $28 \mathrm{~kg} / \mathrm{m}^{2}$ or greater; $\mathrm{OR}_{10}$ represented the effect of hypertension on individuals who had a higher HbA1c level and BMI of less than $28 \mathrm{~kg} / \mathrm{m}^{2}$; and $\mathrm{OR}_{01}$ referred to the effect for hypertension whose had a lower HbA1c level and BMI of $28 \mathrm{~kg} / \mathrm{m}^{2}$ or greater. Thus, $\mathrm{OR}_{00}$ referred to the effect for hypertension who had a lower HbA1c level and BMI of less than $28 \mathrm{~kg} / \mathrm{m}^{2}$, which was regarded as the reference category. $\mathrm{RERI}=0, \mathrm{AP}=0$, or $\mathrm{SI}=1$ was considered as representing no additive interaction. Two-sided $p$-values were calculated and $p<0.05$ was considered to be statistically significant.

\section{Results}

Among the 1462 enrolled subjects, the mean age was $59.9 \pm 11.3$ years. Specifically, 692 males $(40.5 \%)$ and 870 females (59.5\%) were included, respectively. Overall, the rates of hypertension, ISH and IDH were 22.4, 9.6 and $4.5 \%$, respectively. Males had a significantly higher rate of hypertension than females $(p=0.004)$. Compared with subjects with normotension $(59.5 \pm 11.4)$, those with hypertension $(61.4 \pm 10.8)$ exhibited a higher mean age $(p=0.008)$. Additionally, there was a remarkable difference in proportion of positive family history of hypertension $(p=0.042)$ between normotensive and hypertensive participants. Individuals with hypertension had a relatively higher smoking rate (32.1\%) than did those with normotension (27.4\%), without any statistically significant difference $(p=0.096)$. Meanwhile, no statistically significant differences in educational level $(p=0.068)$, marital status $(p=0.226)$, or income $(p=0.806)$ were observed. As for the obesity indices, both BMI $(p<0.001)$ and WC $(p<$ 0.001 ) were proven to be dramatically upregulated in the hypertensive subjects relative to in the normotensive ones. Similarly, SBP $(p<0.001)$, DBP $(p<0.001)$, FPG $(p=$ $0.037)$, TG $(p<0.001)$, and HbA1c $(p=0.002)$ varied markedly between the groups. The characteristics of enrolled subjects are described in detail in Table 1.

The results of HbA1c expression and the risks of hypertension, ISH, and IDH in nondiabetic subjects based on logistic regression analysis are listed in Table 2. The prevalence of hypertension was predominantly elevated with an increase in the quartile of HbA1c ( $p$ for trend $<$ 0.001 ). In the untreated model, there was a remarkable upregulation of the risk of hypertension across the quartiles of HbA1c, and the ORs ( $95 \% \mathrm{CI}$ ) were 1.00 (ref), 1.31 (0.90-1.92), 2.13 (1.48-3.06), and 2.57 (1.79-3.70), respectively. For the adjusted model, in contrast with the lowest HbA1c quartile, the OR $(95 \% \mathrm{CI})$ was 1.90 (1.282.80) for the highest HbA1c quartile. Meanwhile, the risk of ISH was also significantly increased with HbA1c level in Q4 group than that in Q1 group (OR: 2.23, 95\% CI: 1.47-3.71). The results also indicated that the per-unit increase in HbA1c would significantly enhance the risk of hypertension by 1.23 -fold and the risk of ISH by 1.39 -fold, respectively. However, no significant relationship between the HbA1c level and IDH risk was observed (OR: 1.78, 95\% CI: 0.82-3.84). In Fig. 1, the ROC curve analysis suggested that the best threshold of HbA1c for predicting the risk of hypertension was $4.95 \%$.

As represented in Table 3, the participants were separated into four subgroups based on HbA1c level and other factors. After normalizing for confounders, the subjects with higher HbA1c level and a family history of hypertension simultaneously exhibited the highest OR $(2.96,95 \%$ CI: $1.90-4.62)$. It was estimated from AP $(0.37,95 \%$ CI: 0.05-0.70) that there was a combined effect of HbA1c and family history of hypertension on the risk of hypertension rather than from RERI $(1.12,95 \% \mathrm{CI}:-0.17-2.40)$ or SI (2.31, 95\% CI: 0.83-6.44). Participants with alternative 
Table 1 Basic characteristic of the enrolled participants

\begin{tabular}{|c|c|c|c|c|}
\hline Variables & $\begin{array}{l}\text { Total } \\
(N=1462)\end{array}$ & $\begin{array}{l}\text { Normtension } \\
(N=1135)\end{array}$ & $\begin{array}{l}\text { Hypertension } \\
(N=327)\end{array}$ & $P$ value \\
\hline Gender & & & & $0.004^{1}$ \\
\hline Male(n(\%)) & $692(40.5)$ & $437(38.5)$ & $155(47.4)$ & \\
\hline Female $(n(\%))$ & $870(59.5)$ & $698(61.5)$ & $172(52.6)$ & \\
\hline Mean age (SD) & $59.9(11.3)$ & $59.5(11.4)$ & $61.4(10.8)$ & $0.008^{2}$ \\
\hline Educational level & & & & $0.068^{1}$ \\
\hline Middle school graduate or lower (n(\%)) & $467(31.9)$ & $349(30.7)$ & $118(36.1)$ & \\
\hline High school graduate or higher(n(\%)) & $995(68.1)$ & $786(69.3)$ & $209(63.9)$ & \\
\hline Marital status & & & & $0.226^{1}$ \\
\hline Currently married (n(\%)) & $1234(84.4)$ & $951(83.8)$ & $283(86.5)$ & \\
\hline Currently not married (n(\%)) & $228(15.6)$ & $184(16.2)$ & $44(13.5)$ & \\
\hline Income (yuan) & & & & $0.806^{1}$ \\
\hline$<=2000(\mathrm{n}(\%))$ & $805(55.1)$ & $623(54.9)$ & $182(55.7)$ & \\
\hline$>2000(n(\%))$ & $657(44.9)$ & $512(45.1)$ & $145(44.3)$ & \\
\hline Family history of hypertension(n(\%)) & $266(18.2)$ & $194(17.1)$ & $72(22.0)$ & $0.042^{1}$ \\
\hline Smoking(\%) & $416(28.5)$ & $311(27.4)$ & $105(32.1)$ & $0.096^{1}$ \\
\hline BMI $\left(\mathrm{kg} / \mathrm{m}^{2}\right)\left(\mathrm{M}\left(\mathrm{P}_{25}, \mathrm{P}_{75}\right)\right)$ & $24.3(22.1,26.5)$ & $23.8(21.9,26.1)$ & $25.5(23.6,27.7)$ & $<0.001^{3}$ \\
\hline$W C(\mathrm{~cm})\left(\mathrm{M}\left(\mathrm{P}_{25}, \mathrm{P}_{75}\right)\right)$ & $85.0(80.0,91.0)$ & $83.0(78.0,90.0)$ & $90.0(83.0,96.0)$ & $<0.001^{3}$ \\
\hline $\mathrm{SBP}(\mathrm{mmHg})\left(\mathrm{M}\left(\mathrm{P}_{25}, \mathrm{P}_{75}\right)\right)$ & $132(125,140)$ & $130(120,135)$ & $150(145,160)$ & $<0.001^{3}$ \\
\hline $\mathrm{DBP}(\mathrm{mmHg})\left(\mathrm{M}\left(\mathrm{P}_{25}, \mathrm{P}_{75}\right)\right)$ & $80(72,85)$ & $80(70,83)$ & $90(80,100)$ & $<0.001^{3}$ \\
\hline $\mathrm{FPG}(\mathrm{mmol} / \mathrm{L})\left(\mathrm{M}\left(\mathrm{P}_{25}, \mathrm{P}_{75}\right)\right)$ & $4.9(4.5,5.4)$ & $4.8(4.4,5.3)$ & $4.9(4.5,5.5)$ & $0.037^{3}$ \\
\hline $\mathrm{TG}(\mathrm{mmol} / \mathrm{L})\left(\mathrm{M}\left(\mathrm{P}_{25}, \mathrm{P}_{75}\right)\right)$ & $1.4(0.9,1.9)$ & $1.3(0.9,1.8)$ & $1.6(1.1,2.3)$ & $<0.001^{3}$ \\
\hline $\mathrm{HbA1c}(\%)\left(M\left(P_{25}, P_{75}\right)\right)$ & $5.0(4.4,5.6)$ & $4.9(4.4,5.5)$ & $5.1(4.6,5.8)$ & $0.002^{3}$ \\
\hline
\end{tabular}

${ }^{1}:$ Chi-squared test; ${ }^{2}$ :t-test; ${ }^{3}$ : Wilcoxon rank sum test

positive hypertension or general obesity showed a dramatically aggravated risk of hypertension in comparison with those with no positive $\mathrm{HbA} 1 \mathrm{c}$ level and general obesity (OR: 2.37, 95\% CI: $1.69-3.33$ and OR: 1.79, 95\% CI: 1.25-2.58, respectively). However, no noteworthy synergistic interaction was observed between HbA1c and general obesity (RERI: 1.12, 95\%
CI: -0.18 to 2.42 ; AP: $0.24,95 \% \mathrm{CI}:-0.01$ to 0.49 ; and SI: 1.44, 95\% CI: 0.91-2.27). Concerning abdominal obesity, the HbA1c $(+)$ and abdominal obesity $(+)$ subjects exhibited a higher risk of developing hypertension relative to the reference group (OR: 4.02, 95\% CI: 2.815.74). There was a conspicuous additive interaction between the above parameters on hypertension (RERI: 1.48,

Table $2 \mathrm{HbA} 1 \mathrm{C}$ levels and risk of hypertension, ISH,IDH in non-diabetic population by logistic regression analysis

\begin{tabular}{|c|c|c|c|c|c|c|}
\hline & & \multicolumn{4}{|c|}{ Quartiles of $\mathrm{HbA} 1 \mathrm{c}$} & \multirow{2}{*}{$\begin{array}{l}\mathrm{p} \text { for } \\
\text { trend }\end{array}$} \\
\hline & & $\overline{\mathrm{Q} 1}$ & Q2 & Q3 & Q4 & \\
\hline \multirow[t]{4}{*}{ Hypertension } & Unadjusted model & 1.00 (ref) & $1.31(0.90-1.92)$ & $2.13(1.48-3.06)$ & $2.57(1.79-3.70)$ & $<0.001$ \\
\hline & Adjusted model ${ }^{1}$ & 1.00 (ref) & $1.16(0.78-1.74)$ & $1.88(1.28-2.75)$ & $1.90(1.28-2.80)$ & \\
\hline & Continuous (per 1 SD) ${ }^{1}$ & $1.23(1.08-1.40)$ & & & & \\
\hline & Unadjusted model & 1.00 (ref) & $1.30(0.69-2.43)$ & $2.05(1.15-3.65)$ & $2.76(1.57-4.84)$ & $<0.001$ \\
\hline \multirow[t]{3}{*}{ ISH } & Adjusted model ${ }^{1}$ & 1.00 (ref) & $1.28(0.68-2.42)$ & $1.87(1.04-3.37)$ & $2.23(1.47-3.71)$ & \\
\hline & Continuous (per 1 SD) ${ }^{1}$ & $1.39(1.17-1.67)$ & & & & \\
\hline & Unadjusted model & 1.00 (ref) & $1.48(0.70-3.13)$ & $1.74(0.83-3.64)$ & $1.80(0.85-3.80)$ & 0.106 \\
\hline \multirow[t]{2}{*}{$\mathrm{IDH}$} & Adjusted model ${ }^{1}$ & 1.00 (ref) & $1.44(0.68-3.10)$ & $1.85(0.87-3.90)$ & $1.78(0.82-3.84)$ & \\
\hline & Continuous (per 1 SD) ${ }^{1}$ & $1.20(0.94-1.53)$ & & & & \\
\hline
\end{tabular}




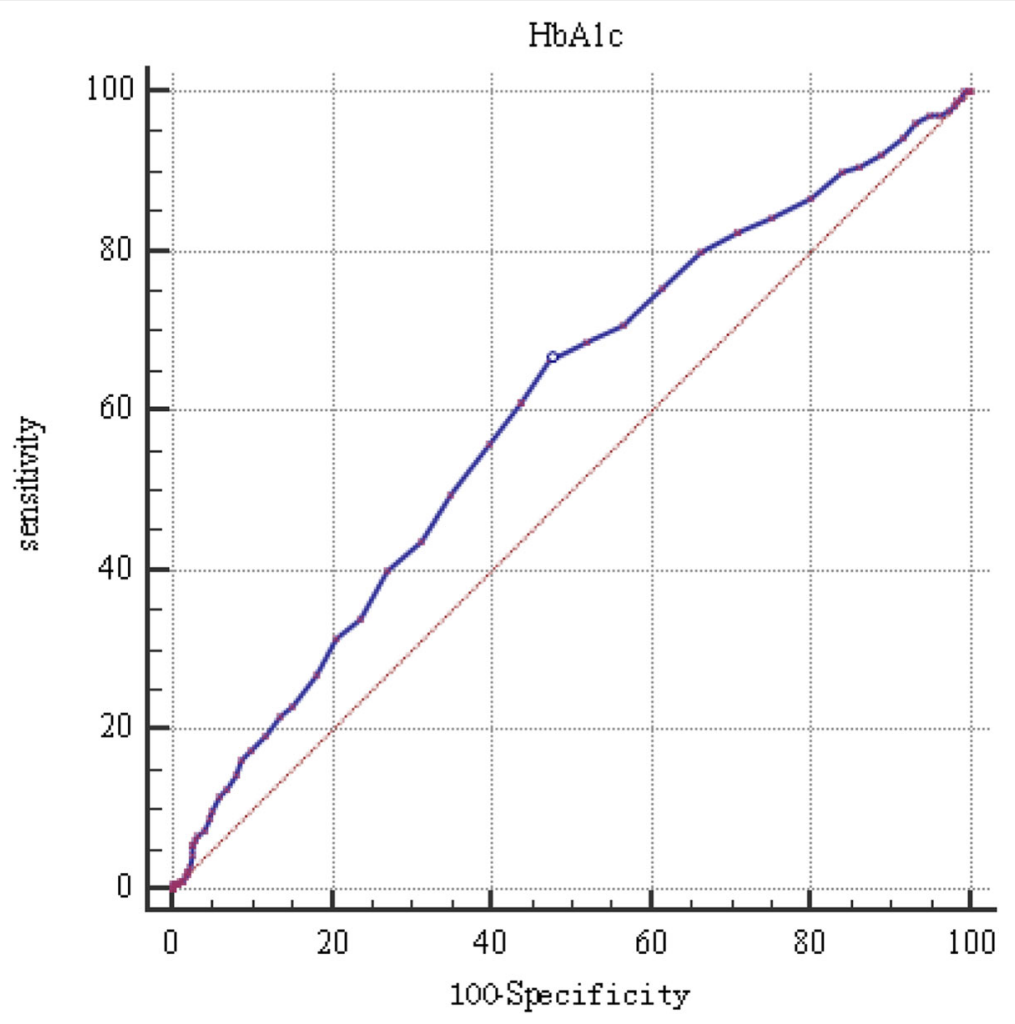

Fig. $1 \mathrm{ROC}$ curve analysis of HbA1c and hypertension risk in non-diabetic subjects

Table 3 interaction analysis of $\mathrm{HbA1c}$ with other factors on risk of hypertension

\begin{tabular}{|c|c|c|c|c|c|}
\hline \multicolumn{2}{|c|}{ Variables } & \multirow[t]{2}{*}{$\mathrm{OR}^{1}(95 \% \mathrm{Cl})$} & \multicolumn{3}{|c|}{ Measures of interaction ${ }^{1}$} \\
\hline $\mathrm{HbA1c}$ & Family history of hypertension & & RERI & AP & $\mathrm{SI}$ \\
\hline- & - & 1 (ref) & $1.12(-0.17-2.40)^{2}$ & $0.37(0.05-0.70)^{3}$ & $2.31(0.83-6.44)^{2}$ \\
\hline - & + & $1.31(0.80-2.13)$ & & & \\
\hline+ & - & $1.54(1.14-2.08)$ & & & \\
\hline+ & + & $2.96(1.90-4.62)$ & & & \\
\hline $\mathrm{HbA} 1 \mathrm{c}$ & General obesity & & & & \\
\hline- & - & 1 (ref) & $1.12(-0.18-2.42)^{2}$ & $0.24(-0.01-0.49)^{2}$ & $1.44(0.91-2.27)^{2}$ \\
\hline - & + & $1.98(1.27-3.09)$ & & & \\
\hline+ & - & $2.59(1.71-3.92)$ & & & \\
\hline+ & + & $4.69(3.17-6.94)$ & & & \\
\hline $\mathrm{HbA} 1 \mathrm{c}$ & Abdominal obesity & & & & \\
\hline - & - & 1 (ref) & $1.48(0.38-2.58)^{3}$ & $0.37(0.14-0.60)^{3}$ & $1.96(1.06-3.62)^{3}$ \\
\hline - & + & $2.10(1.41-3.12)$ & & & \\
\hline+ & - & $1.44(0.92-2.22)$ & & & \\
\hline+ & + & $4.02(2.81-5.74)$ & & & \\
\hline
\end{tabular}

:adjusted for other variables;

${ }^{2}: p>0.05$;

${ }^{3}: p<0.05 ;$ 
95\% CI: 0.38-2.58; AP: 0.37, 95\% CI: 0.14-0.60, and SI: $1.96,95 \%$ CI: $1.06-3.62$, respectively).

\section{Discussion}

This population-based survey demonstrated that higher HbA1c levels dramatically aggravate the risk of hypertension in subjects without diabetes, further emphasizing the role of abnormal glucose metabolism in the pathogenesis of hypertension. Owing to specific merits, HbA1c generally serves as an effective indicator in the management of diabetes over FPG or postload plasma glucose. First, HbA1c has less biological variability and higher stability and, second, HbA1c could be less affected by relevant factors, such as acute infection, shortterm lifestyle alterations, and recent eating behaviors [25]. Third, FPG only reflects the immediate glycemia level at the time of a single measurement; in contrast, HbA1c can stably indicate chronic glycemia levels, which reflect variations in average glycemia level across nearly two to 3 months. A cohort study consisting of 31,148 adults revealed that HbA1c was closely correlated with all-cause mortality and coronary heart disease in contrast to the fasting glucose [26]. Arbel et al. [27] investigated the relationship between glucometabolic markers (including admission glucose, FPG, and HbA1c) and the severity of coronary artery disease in nondiabetic patients, which indicated that only HbA1c was associated with the severity of coronary artery disease.

The relationship between glycemic control and hypertension can be explained by several possible mechanisms. First, function deficits of pancreatic $\beta$ cells and IR could be indicated by the expression, of HbAlc $[9,10]$. It was well-recognized that IR was the common pathophysiological foundation for the development of both type 2 diabetes and hypertension [28]. When the homeostasis model assessment of IR was applied to estimate IR, it was revealed that the result was dramatically upregulated across the quartile levels of HbA1c in Korean males without diabetes [29]. Additionally, HbA1c was also reported to be one of the best indices for identifying IR in obese nondiabetic individuals [10]. Second, numerous studies have implied that HbA1c may play a role in arterial stiffness via proinflammatory cell signaling and oxidative stress $[30,31]$. It was demonstrated in a crosssectional survey containing 11,014 Chinese participants that brachial-ankle pulse wave velocity and central SBP were markedly elevated across the quartiles of HbA1c [32]. Third, increased levels of HbAlc can contribute to endothelial damage that would further promote the release of endothelin from endothelial cells and inhibit the production of nitric oxide and prostacyclin, which would result in vasomotor dysfunction and further increase the BP [25, 33]. Moreover, it has been reported that there is a direct association between $\mathrm{HbAlc}$ and the activation of the renin-angiotensin- aldosterone-system [34]. Also, it has been indicated in clinical research that blood lipids could be positively regulated by the high level of HbAlc, which contributed to the increase in blood viscosity and furthered the incidence of cardiovascular diseases [25]. With the increase in HbA1c level, the number of cardiovascular risk factors clustering, including FPG, high total cholesterol, high TG, and high low-density lipoprotein cholesterol, was also dramatically upregulated [35].

To our knowledge, limited researches have investigated the influence of higher HbA1c levels on hypertension risk, and the conclusions were inconsistent. A cohort study of Americans including 9603 participants demonstrated that higher baseline HbA1c concentrations were predominantly associated with the incidence of hypertension independently of obesity indices and other factors in diabetic as well as nondiabetic individuals [36]. Similarly, in a women's health study, 19,858 American women initially without diabetes were followed up with for a median of 11.6 years. The subjects were grouped based on HbA1c by clinical quintiles, and the hazard ratio (HR) for the highest HbA1c quintile in comparison with that of the lowest was statistically significant in both the univariable analysis and multivariable analysis [37]. However, when grouping HbA1c by quintiles, the above significant association was eliminated after normalizing for BMI. Moreover, elevated HbA1c levels dramatically aggravated the risk of hypertension in an independent manner even after normalizing traditional risk factors in general middle-aged and elderly Chinese subjects [38]. Besides that, the Framingham Heart Study demonstrated that high HbA1c expression was associated with the prevalence of hypertension, but it was only based on a univariate analysis [39]. In a Japanese cohort study with 5 years of follow-up, 9584 individuals were investigated, and elevated expressions of HbA1c were not associated with an increased risk of developing hypertension in the multivariable analysis [40]. An increment in HbA1c level was also reported not to be independently involved in the future development of hypertension among the Israeli population [41]. Kroke et al. [42] revealed that there was a nonsignificant relationship between HbA1c and arterial hypertension in nondiabetic participants; nevertheless, arterial hypertension was defined as a BP of $160 / 95 \mathrm{mmHg}$ or greater. These inconsistencies may be explained by the diversity of HbA1c according to age, gender, and ethnicity.

Additionally, our results indicated a significant relationship between the HbA1c level and ISH risk but not IDH risk. Similarly, IR as indicated by TG-glucose index was suggested to be correlated with ISH risk rather than IDH risk [43]. In patients with type 2 diabetes, there was also an independent association between the duration of diabetes and ISH risk, suggesting that chronic hyperglycemia 
may play an essential role in the pathogenesis of ISH [44]. A cross-sectional investigation among middle-aged and elderly adults in China suggested that patients with ISH had a significantly higher prevalence of impaired glucose regulation and diabetes than those with IDH [45]. Overall, the prevalence of IDH was lower than that of ISH in hypertension subtypes. The distribution of hypertension subtypes was affected by various factors, like economic conditions, gender, and age [46]. As is known, ISH independently reflects arterial stiffness and is more common in the elderly, while IDH is independently related to an increase in arteriolar resistance and is more common in young and middle- aged people. However, it should be considered that most of the subjects enrolled in this survey were middle-aged and elderly adults, and the number of cases of IDH in this study was relatively small. Therefore, the association between HbA1c and IDH risk needs to be further explored, especially in young adults.

This study further demonstrated that HbAlc plays a significantly interactive role in the impact of abdominal obesity rather than general obesity on the risk of hypertension. Several studies have suggested that abdominal fat distribution may be more strongly related to adverse outcomes, such as cardiovascular diseases, than BMI. It is well acknowledged that obesity is a predominant risk factor of hypertension [47]. When evaluating the predicted performance outcomes of different obesity indices on hypertension, WC was superior to BMI based on ROC curve analysis [48]. It was illustrated that obesity was dramatically associated with elevated HbA1c levels in diabetic as well as nondiabetic subjects. Obesity can cause IR and result in poor glycemic control [25]. In addition, adipocytokines secreted from adipose tissue were involved in insulin resistance and beta cell dysfunction [49]. Furthermore, the occurrence of hypertension was a combinative consequence of genetic and environmental effects. A family history of hypertension was a simple and alternative genetic indicator. Moreover, a case-control study among Chinese individuals proved that a family history of hypertension and BMI had a positive impact on hypertension [17]. Our results also illustrated that HbAlc had a remarkable interaction with a family history of hypertension on the risk of hypertension.

There were several limitations in our study. First, the causality of the results failed to be inferred as this was a cross-sectional study. Second, the influences of various antihypertensive drugs on glucose metabolism varied but were not investigated in depth. However, it was shown that the effects of antihypertensive medication such as diuretics on HbA1c seemed to be of minor importance in diabetes as well as in nondiabetic individuals $[50,51]$. Third, BP was measured in a single session and may be influenced by various external factors.

\section{Conclusion}

This study demonstrated the independent and interactive effect of HbA1c on the risk of hypertension in nondiabetic Chinese subjects, suggesting that abnormal glucose metabolism has an essential role in the pathogenesis of hypertension. Further cohort studies with more research population are urgent to verify our results, and the underlying mechanism needs to be elucidated, which could eventually support more effective prevention strategies for hypertension.

\section{Abbreviations \\ ISH: Isolated systolic hypertension; IDH: Isolated diastolic hypertension; RERI: Relative excess risk due to interaction; AP: Attributable proportion due to interaction; SI: Synergy index; BMI: Body mass index; FPG: Fasting plasma glucose; BP: Blood pressure; SBP: Systolic BP; DBP: Diastolic BP; WC: Waist circumference; TG: Triglycerides; SD: Standard deviations; Cls: Confidence intervals: IR: Insulin resistance}

\section{Acknowledgments}

We are grateful to all professionals and participants of the study. We thank LetPub (www.letpub.com) for its linguistic assistance during the preparation of this manuscript.

\section{Authors' contributions}

WXS provided funding and designed the work. SJ and WXS conducted data analysis and interpretation. ZYY, JYH collected the data. WNN helped prepare the Methods section of the paper and draw the Tables. SJ drafted the manuscript. GHQ and WXS revised the manuscript critically and provided continuous guidance throughout the study. All authors read and approved the final manuscript.

\section{Funding}

Our work was financed by the National Natural Science Foundation of China (number:81373100) and Key Project of Natural Science Fund of Bengbu Medical college (number: BYKY1823ZD). The funders had no part in the study design, data collection, data analysis, interpretation of data or in writing the manuscript.

\section{Availability of data and materials}

The datasets used and/or analyzed during the current study are available from the corresponding author on reasonable request.

Ethics approval and consent to participate

This study was approved by the Ethics Committee of Bengbu Medical College. Written informed consent was obtained from all participants.

Consent for publication

Not Applicable.

\section{Competing interests}

The authors report no conflicts of interest.

\section{Author details}

${ }^{1}$ School of public health, Bengbu medical college, Bengbu 233000, Anhui Province, China. ${ }^{2}$ Department of general medicine, The First Affiliated Hospital of Bengbu Medical College, Bengbu 233004, Anhui Province, China. ${ }^{3}$ Bengbu health board, 568 Nanhu road, Bengbu 233000, Anhui Province, China.

Received: 26 August 2019 Accepted: 30 April 2020

Published online: 12 May 2020

\section{References}

1. Fisher NDL, Curfman G. Hypertension-A Public Health Challenge of Global Proportions [J]. JAMA,2018,17,1757-9. 
2. Wang Z, Chen Z, Zhang L, Wang X, Hao G, Zhang Z, et al. Status of hypertension in status of hypertension in china: results from the china hypertension survey, 2012-2015 [J]. Circulation. 2018;137(22):2344-56.

3. Redfern A, Peters SAE, Luo R, Cheng Y, Li C, Wang J, et al. Sex differences in the awareness, treatment, and control of hypertension in China: a systematic review with meta-analyses [J]. Hypertens Res. 2019;42(2):273-83.

4. Chen J, Zhang C, Wu Y, Zhang D. Association between hypertension and the risk of Parkinson's disease: a meta-analysis of analytical studies [J]. Neuroepidemiology. 2019;52(3-4):181-92.

5. He J, Klag MJ, Wu Z, Whelton PK. Stroke in the People's Republic of China. II. Meta-analysis of hypertension and risk of stroke []]. Stroke. 1995;26(12): 2228-32.

6. Han H, Guo W, Shi W, Yu Y, Zhang Y, Ye X, et al. Hypertension and breast cancer risk: a systematic review and meta-analysis [J]. Sci Rep. 2017;7:44877.

7. Yang G, Wang Y, Zeng Y, et al. Rapid health transition in China, 1990-2010: findings from the global burden of disease study 2010[J]. Lancet. 2013;381: 1987-2015.

8. Ferrannini E, Cushman WC. Diabetes and hypertension: the bad companions [J]. Lancet. 2012;380:601-10.

9. Chehregosha H, Khamseh ME, Malek M, Hosseinpanah F, Ismail-Beigi F. A view beyond $\mathrm{HbA1c}$ : role of continuous glucose monitoring [J]. Diabetes Ther. 2019;10(3):853-63.

10. Boursier G, Sultan A, Molinari N, Maimoun L, Boegner C, Picandet M, et al. Triglycerides and glycated hemoglobin for screening insulin resistance in obese patients [J]. Clin Biochem. 2018;53:8-12.

11. Seino Y, Nanjo K, Tajima N, et al. Report of committee on the classification and diagnostic criteria of diabetes mellitus []]. J Diabetes Investig. 2010;1(5): 212-28.

12. Matsushita K, Blecker S, Pazin-Filho A, et al. The association of hemoglobin a1 $\mathrm{c}$ with incident heart failure among people without diabetes: the atherosclerosis risk in communities study []]. Diabetes. 2010;59(8):2020-6.

13. Lee $\mathrm{YH}$, Shin MH, Choi JS, et al. HbA1c is significantly associated with arterial stiffness but not with carotid atherosclerosis in a community-based population without type 2 diabetes: the Dong-gu study [J]. Atherosclerosis. 2016;247:1-6.

14. $\mathrm{Wu} \mathrm{H}, \mathrm{Xu}$ J, Zhuo L, et al. Comparison of risk factors associated with hypertension subtypes by classification tree method in Tongshan County of Jiangsu Province, China [J]. Am J Hypertens. 2009;22(12):1287-94.

15. Franklin SS, Barboza MG, Pio JR, et al. Blood pressure categories, hypertensive subtypes, and the metabolic syndrome [J]. J Hypertens. 2006; 24:2009-16.

16. Nishiyama M, Kimijima M, Muto T, Kimura K. Presence of an interaction between smoking and being overweight increases risks of hypertension diabetes, and cardiovascular disease in outpatients with mood disorders [J]. Environ Health Prev Med. 2012;17(4):285-91.

17. Li AL, Peng Q, Shao YQ, Fang X, Zhang YY. The effect of body mass index and its interaction with family history on hypertension: a case-control study [J]. Clin Hypertens. 2019;25:6.

18. Alberti KG, Zimmet PZ. Definition, diagnosis and classification of diabetes mellitus and its complications. Part 1: diagnosis and classification of diabetes mellitus provisional report of a WHO consultation [J]. Diabet Med. 1998;15:539-53.

19. Revision Committee of the Guidelines for the Prevention and Treatment of Hypertension in China. The Guidelines for the Prevention and Treatment of Hypertension in China (Revision 2016) [M]. Beijing: People Public Health Publishing Company; 2016.

20. Writing Group of. Chinese guidelines for the Management of Hypertension. 2010 Chinese guidelines for the management of hypertension [J]. Chine J Cardiology. 2010;2011(39):579-616.

21. Chen C, Lu FC, Department of Disease Control Ministry of Health, PR China. The guidelines for prevention and control of overweight and obesity in Chinese adults [J]. Biomed EnvironSci. 2004;17(Suppl):1-36.

22. Chu JR, Gao JL, Zhao SP, et al. Blood lipid abnormity prevention guidance in Chinese adult [J]. Chin Circ J. 2016:31(10):937-53.

23. Andersson T, Alfredsson L, Kallberg $\mathrm{H}$, et al. Calculating measures of biological interaction [J]. Eur J Epidemiol. 2005;20:575-9.

24. Knol MJ, VanderWeele TJ, Groenwold RH, et al. Estimating measures of interaction on an additive scale for preventive exposures [J]. Eur J Epidemiol. 2011;26(6):433-8.

25. Prasad K. Does hba1cc play a role in the development of cardiovascular diseases? [J]. Curr Pharm Des. 2018;24(24):2876-82.
26. Metcalf PA, Kyle C, Kenealy $\mathrm{T}$, Jackson RT. HbA1c in relation to incident diabetes and diabetes-related complications in non-diabetic adults at baseline [J]. J Diabetes Complicat. 2017;31(5):814-23.

27. Arbel Y, Zlotnik M, Halkin A, Havakuk O, Berliner S, Herz I, et al. Admission glucose, fasting glucose, HbAlc levels and the SYNTAX score in nondiabetic patients undergoing coronary angiography [J]. Clin Res Cardiol. 2014;103(3):223-7.

28. Wang F, Han L, Hu D. Fasting insulin, insulin resistance and risk of hypertension in the general population: a meta-analysis [J]. Clin Chim Acta. 2017:464:57-63.

29. Jung $\mathrm{CH}$, Rhee EJ, Kim KJ, Kim BY, Park SE, Chang Y, et al. Relationship of glycated hemoglobin A1c, coronary artery calcification and insulin resistance in maleswithout diabetes [J]. Arch Med Res. 2015;46(1):71-7.

30. Saisho Y. Glycemic variability and oxidative stress: a link between diabetes and cardiovascular disease? [J]. Int J Mol Sci. 2014;15(10):18381-406.

31. Chen Y, Huang Y, Li X, Xu M, Bi Y, Zhang Y, et al. Association of arterial stiffness with $\mathrm{HbA1c}$ in 1,000 type 2 diabetic patients with or without hypertension [J]. Endocrine. 2009;36(2):262-7.

32. Zeng $\mathrm{Q}$, Dong $S Y$, Wang $M L$, Wang WM, Li JM, Dai ZX, et al. Serum glycated albumin, glycated hemoglobin, and arterial stiffness in a general Chinese population [J]. Clin Chim Acta. 2017:468:33-8.

33. Chugh SN, Dabla S, Jain V, Chugh K, Sen J. Evaluation of endothelial function and effect of glycemic control (excellent vs. poor/ fair control) on endothelial function in uncontrolled type 2 diabetes mellitus [J]. J Assoc Physicians India. 2010;58:478-80.

34. Griffin TP, Wall D, Browne GA, Dennedy MC, O'Shea PM. Associations between glycaemic control and activation of the renin angiotensin aldosterone system in participants with type 2 diabetes mellitus and hypertension [J]. Ann Clin Biochem. 2018;55(3):373-84.

35. Dizdarevic-Bostandzic A, Begovic E, Burekovic A, Velija-Asimi Z, Godinjak A, Karlovic V. Cardiovascular risk factors in patients with poorly controlled diabetes mellitus [J]. Med Arch. 2018;72(1):13-6.

36. Bower JK, Appel LJ, Matsushita K, Young JH, Alonso A, Brancati FL, Selvin E. Glycated hemoglobin and risk of hypertension in the atherosclerosis risk in communities study [J]. Diabetes Care. 2012;35(5):1031-7.

37. Britton KA, Pradhan AD, Gaziano JM, Manson JE, Ridker PM, Buring JE, Sesso HD. Hemoglobin A1c, body mass index, and the risk of hypertension in women [J]. Am J Hypertens. 2011;24(3):328-34.

38. Hidru TH, Yang X, Xia Y, Ma L, Li HH. The relationship between plasma markers and Essentia hypertension in middle-aged and elderly Chinese population: a community based cross-sectional study [J]. Sci Rep. 2019;9(1): 6813.

39. Singer DE, Nathan DM, Anderson KM, Wilson PW, Evans JC. Association of $\mathrm{HbA} 1 \mathrm{c} \mathrm{HbA1c}$ with prevalent cardiovascular disease in the original cohort of the Framingham heart study [J]. Diabetes. 1992;41(2):202-8.

40. Heianza Y, Arase Y, Kodama S, Hsieh SD, Tsuji H, Saito K, et al. Fasting glucose and $\mathrm{HbA1C}$ levels as risk factors for the development of hypertension in Japanese individuals: Toranomon hospital health management center study 16(TOPICS 16) [J]. J Hum Hypertens. 2015;29(4): 254-9.

41. Geva M, Shlomai G, Berkovich A, Maor E, Leibowitz A, Tenenbaum A, et al. The association between fasting plasma glucose and glycated hemoglobin in the prediabetes range and future development of hypertension [J]. Cardiovasc Diabetol. 2019;18(1):53.

42. Kroke A, Liese AD, Keil $U$, Boeing $H$. Arterial hypertension and glycemia in non-diabetic subjects: is there an association independent of obesity [J]? Diabetes Metab Res Rev. 1999;15(2):99-105.

43. Jian S, Su-Mei N, Xue C, et al. Association and interaction between triglyceride- glucose index and obesity on risk of hypertension in middleaged and elderly adults []]. Clin Exp Hypertens. 2017;39(8):732-9.

44. Ko GT, Cockram CS, Chow CC, et al. Effects of body mass index, plasma glucose and cholesterol levels on isolated systolic hypertension [J]. Int J Cardiol. 2005;101(3):429-33.

45. Li R, Zhang SH, Ren W, et al. Metabolic characteristics of blood glucose and blood lipid in patients with different types of hypertension in some communities of Chongqing [J]. Chin J Clin Rehabil. 2005;21(9):1-3.

46. Wu Y, Liu F, Adi D, et al. Association between carotid atherosclerosis and different subtypes of hypertension in adult populations: a multiethnic study in Xinjiang, China [J]. PLoS One. 2017;12(2):e0171791.

47. Jiang SZ, Lu W, Zong XF, Ruan HY, Liu Y. Obesity and hypertension [J]. Exp Ther Med. 2016;12(4):2395-9. 
48. Janghorbani M, Aminorroaya A, Amini M. Comparison of different obesity indices for predicting incident hypertension [J]. High Blood Press Cardiovasc Prev. 2017;24(2):157-66.

49. Guzik TJ, Mangalat D, Korbut R. Adipocytokines -novel link between inflammation and vascular function [J]? J Physiol Pharmacol. 2006;57(4):505-28.

50. Hirst JA, Farmer AJ, Feakins BG, Aronson JK, Stevens RJ. Quantifying the effects of diuretics and $\beta$-adrenoceptor blockers on glycaemic control in diabetes mellitus-a systematic review and meta-analysis [J]. Br J Clin Pharmacol. 2015;79(5):733-43.

51. Roth J, Muller N, Kuniss N, et al. Association between Glycaemic control and the intake of thiazide diuretics, Beta blockers and levothyroxine in people without diabetes []]. Exp Clin Endocrinol Diabetes. 2019;1.

\section{Publisher's Note}

Springer Nature remains neutral with regard to jurisdictional claims in published maps and institutional affiliations.

Ready to submit your research? Choose BMC and benefit from:

- fast, convenient online submission

- thorough peer review by experienced researchers in your field

- rapid publication on acceptance

- support for research data, including large and complex data types

- gold Open Access which fosters wider collaboration and increased citations

- maximum visibility for your research: over $100 \mathrm{M}$ website views per year

At $B M C$, research is always in progress.

Learn more biomedcentral.com/submissions 